\title{
The Professional Quality of Life Among Nurses in Saudi Arabia: A Multi-Centre Study
}

\author{
Maaidah M Algamdi (D) \\ Department of Nursing, Faculty of Applied Medical Sciences, University of Tabuk, Tabuk, Saudi Arabia \\ Correspondence: Maaidah M Algamdi, Department of Nursing, Faculty of Applied Medical Sciences, University of Tabuk, Tabuk, Saudi Arabia, \\ Tel +96656009l866, Email ialghamdi@ut.edu.sa
}

Background: The nursing profession in Saudi Arabia requires attention and support. Assessing Saudi nurses' professional quality of life (ProQOL) is crucial for their future nursing careers and the future of Saudi health care.

Aim: To investigate the level of ProQOL among nurses in Saudi Arabia and its association with personal and professional sociodemographic variables.

Methods: A cross-sectional descriptive study was conducted on a sample of 334 Saudi nurses working in three hospitals and multiple primary health centers. Descriptive analysis, Mann-Whitney U and Kruskal-Wallis tests were used to determine the significant association between sample sociodemographic variables and levels of ProQOL.

Results: A significant difference between compassion satisfaction $(\mathrm{CS})$ and nurses' age ( $\mathrm{p}$-value $=0.008$ ) and years of experience $(p$-value $=0.012)$ was confirmed. The job location $(p$-value $<0.001)$, nurses' department ( $p$-value $=0.003)$, and age $(p$-value $=0.012)$ revealed a significant difference with burnout (BO). Secondary traumatic stress (STS) showed a significant difference with the job location ( $p$-value $<0.001$ ) and nurses' department ( $p$-value $=0.008)$. Overall, Saudi nurses exhibit high levels of CS and moderate levels of BO and STS.

Conclusion: The level of CS was considered good for Saudi nursing professionals; however, the levels of BO and STS require further attention. Enhancing factors related to $\mathrm{CS}$ and solving issues related to compassion fatigue $(\mathrm{CF})$ would improve the nursing profession in Saudi Arabia.

Keywords: compassion satisfaction, compassion fatigue, burnout, secondary traumatic stress, saudi nurses, Saudi Arabia

\section{Introduction}

The nursing profession in Saudi Arabia requires attention, particularly because of the rapidly growing population and development of new health care facilities. ${ }^{1,2}$ The first objective of the national transformation program based on Saudi Vision 2030 is to provide easy access to health care services by increasing the proportion of residential areas covered by health care services, allowing more people to benefit from those services (available at: https://vision2030.gov.sa/en/ programs/NTP). At the same time, the nursing profession in Saudi Arabia faces many challenges due to stressful workloads, burnout (BO), and nurses' intention to leave. ${ }^{3-7}$

Nurses who provide direct patient care are often faced with scenarios that require emotional endurance. This can have positive consequences, such as satisfaction and resilience, or negative consequences that include depression, anxiety, stress, and fatigue. ${ }^{8}$ As described by Stamm, ${ }^{9}$ these factors can be grouped under the theory of professional quality of life (ProQOL). This theory comprises two aspects of an individual's feelings toward their work: compassion satisfaction (CS), the pleasant feeling inherent to nursing, and compassion fatigue (CF), the unpleasant consequence resulting from nursing care. ${ }^{10} \mathrm{CS}$ reflects the satisfactory feeling generated through helping others. It is also experienced by nurses who provide comprehensive patient care. ${ }^{11}$ Additionally, Y1lmaz ${ }^{12}$ found that CS is an incentive to provide care that results from previous good work. It is the opposite of $\mathrm{CF}$, which occurs due to the emotional demand of coping with stressors that can negatively influence ProQOL. ${ }^{8,13}$ 
Nurses face many types of stressors due to their patients' conditions, particularly regarding oncology patients, critical care patients, women in labour, and neonatal and intensive care unit patients, that influence their ProQOL. ${ }^{6,14-17}$ Nurses experience both of these aspects of ProQOL consistently. Their experience with CF may be due to either BO or secondary traumatic stress (STS). ${ }^{9} \mathrm{BO}$ occurs due to stressful conditions, such as heavy workloads, staff shortages, or long shifts, and has a negative influence on nurses. ${ }^{18}$ Likewise, STS is a consequence of BO-also called post-traumatic stress - experienced by nurses who suffer from extreme stressful issues and high workloads. ${ }^{19}$ Nurses' feelings of empathy, their bond with their patients, and other personal factors could be predisposing factors of STS. ${ }^{20}$ STS occurs due to continued exposure to complicated, stressful situations, such as tertiary hospitals, emergency rooms, or dealing with terminally ill patients. $19,21,22$

Many studies have reported the cultural, educational, and professional challenges nurses face in Saudi Arabia. ${ }^{3-5}$ The ProQOL of the Saudi nursing profession has been explored in specific units, such as intensive care, pediatric oncology, and the emergency care unit reporting high to moderate levels of BO and STS. ${ }^{6,22,23}$ Saudi nurses' ProQOL requires additional exploration due to the governmental transformation of the health care sectors and Saudization (recruiting those with Saudi nationality) of health care professionals, especially within the nursing profession. ${ }^{2,24}$ Therefore, this study was conducted to assess the level of Saudi nurses' ProQOL and sociodemographic related factors. The research questions are as follows: (1) What are the significant differences between the mean scores of the ProQOL subscales and the sociodemographic characteristics of the sample of Saudi nurses? (2) What are the mean scores of the overall ProQOL variables among Saudi nurses? It was assumed that the principal investigator would find a significant relationship between the ProQOL and sociodemographic variables and that personal and work-related variables would have either positive or negative impacts on the care provided by the Saudi nurses.

\section{Materials and Methods}

\section{Sample, Setting, and Design}

A cross-sectional descriptive study was conducted using a convenience sample of Saudi nurses working in several hospitals and primary health centers in Tabuk: the King Khaled Hospital, the King Fahad Hospital, the Maternity and Children's Hospital, and the Eradah Complex for Mental Health. The sample was selected according to the following inclusion criteria: of Saudi nationality, graduated as a nurse, and delivers direct patient care. Exclusion criteria were nurses who work in administrative or academic fields and nursing interns. Given a $95 \%$ confidence interval and a 0.5 margin of error, a sample size of 384 was calculated based on the total number of nurses working in the mentioned settings (approximately 2000). Data were collected using an online survey with the cooperation of coordinators from each hospital and health centre. The survey consisted of two parts: sociodemographic characteristics and the ProQOL scale.

\section{Data Analysis}

Data were checked for completeness and correctness, then coded and entered into IBM SPSS software version 26 (IBM Corp, Armonk, New York). Categorical variables were presented as frequencies and percentages. Continuous variables were presented as mean and standard deviations. The analysis was performed in $95 \%$ confidence interval. The descriptive statistics used to define the sample characteristics. The relationship between socio-demographic characteristics and ProQOL subscales and mean subscale scores were assessed by Mann-Whitney $U$-test and Kruskal-Wallis test. A p-value $<0.05$ indicated a significant correlation.

\section{Instruments}

The researcher used a two-part questionnaire structured as follows: the first section included sociodemographic characteristics, classified as either personal (age, gender, and marital status) or professional (salary, professional classification, educational level, department, and years of experience) items. Units were divided into three categories: critical care units, inpatients, and outpatients. For the second section, an Arabic version of the ProQOL scale (available at: https://proqol.org/proqol-measure), a 30-item questionnaire on a 5-point Likert scale (ranging from $1=$ never to $5=$ 
very often) was used to measure ProQOl among service providers/helpers to assess the positive and negative facets of providing the service. This tool is applicable in the nursing profession and has been widely used in studies across many countries. The questionnaire consisted of three sets of 10 items that reflected specific measures on the ProQOL subscales: CS, BO, and STS. The total score of each subscale was interpreted as either high $(\geq 41)$, moderate (23-41), or low $(\leq 22){ }^{9}$ In this study, the researcher evaluated the Arabic version of the ProQOL questionnaire for internal consistency using Cronbach's alpha among a sample of 334 Saudi nurses. Cronbach's alpha was 0.750 for the total 30 -item ProQOL scale, 0.907 for the CS subscale (10 items), 0.760 for the BO subscale (10 items), and 0.815 for the STS subscale (10 items). This indicated adequate levels of internal consistency and evidence of instrument reliability. ${ }^{25,26}$

\section{Ethical Considerations}

The researcher conducted this study in accordance with the Declaration of Helsinki. Ethical approval was obtained from the Institutional Review Board of the General Directorate of Health Affairs, Tabuk Region (Registration NO.H-07-TU -077). Confidentiality and anonymity were maintained, and no personal identifiers were requested from the participants. The data were collected electronically, and the study aim was explained at the beginning of the survey. Additionally, participants were free to proceed with the questions or withdraw at any point during the survey. Participants consented electronically to participating in the study and to the publishing of the study's findings. Moreover, a trigger warning was issued to inform the participants that some questions may remind them of unpleasant situations that may have occurred over the course of their professional life or of particular patients they may have treated.

\section{Results}

A total of 334 responses were received with an adequate response rate $87 \%{ }^{27}$ Table 1 shows the sample sociodemographic characteristics dominated by female nurses (82.6\%) and individuals between 26 and 30 years old (41\%). More than half of the sample (60\%) was married, and their salary ranged between 11,000 and 15,000 $(56.6 \%)$. Over half of the respondents were nurse technicians $(60.8 \%)$, and more than one-third of the sample worked in the outpatient (39.3\%) or critical care units (37.4\%). Less than $10 \%$ of participants worked at the Eradah Complex of Mental Health (8.7\%). Approximately one-third of the sample had 6-10 years of experience in the nursing field (29.6\%). More than one-third of the sample had a bachelor's degree or a 2-year diploma (38.6\% and 33.5\%, respectively).

The CS, BO, STS subscale scores and mean subscales scores for each socio-demographic characteristic are presented in Table 2. As per CS subscale score, statistically significant differences were seen between different age groups (p-value $=0.008)$, and between years of experience subgroups ( $p$-value $=0.012)$. Nurses aged more than 45 years had higher CS score $(48.40 \pm 1.67)$ than other age groups, and the lowest CS score was seen among 36- to 40-year-old $(38.72 \pm 9.50)$. Among the different experience level, nurses with less than 6 months of experience had the highest CS score (44.14 \pm 7.47), and those with 11 to 15 years of experience had the lowest CS score (38.09 \pm 10.82$)$. Job location played a significant role on $\mathrm{BO}$ subscale score as the psychiatry hospital nurses had a BO score of $30.00 \pm 4.32$, which is significantly higher than any other hospitals ( $\mathrm{p}$-value $<0.001$ ). In-patient department nurses had the highest BO score of $42.09 \pm 7.17$, whereas the critical care department nurses had a BO score of $41.31 \pm 7.33$, and out-patient nurses had a BO score of $40.33 \pm 9.80$ (p-value $=0.003$ ). The BO score was not statistically significantly different for any other socio-demographic characteristics (all p-values $>0.050$ ). Job location also played a significant role for STS score because in-patient nurses had higher STS score $(29.68 \pm 7.93)$ compared to critical care nurses $(28.86 \pm 7.36)$, and out-patient nurses $(26.57 \pm 8.16)$. This difference was statistically significant ( $\mathrm{p}$-value $=0.008)$. STS score was similar for all other studied socio-demographic characteristics (all p-values $>0.050$ ). The mean of subscale scores was highest among the psychiatry hospital nurses (35.68 \pm 3.63 ), p-value $<0.001$ and in-patient department nurses, $33.28 \pm 3.72$, p-value $<0.001$. The mean subscale score was similar to other socio-demographic characteristics.

Subscale levels are presented in Figure 1. The high CS, and moderate BO and STS levels were observed among $57.5 \%, 68.3 \%$, and $71.3 \%$ cases, respectively.

Regarding mean scores for all ProQOL items, there were 30 items; the lowest mean score was seen for item Q29 "I am a very caring person" which was $1.70 \pm 1.031$. The highest mean score of $4.39 \pm 0.955$ was observed for Q24 "I am proud of what I can do to [help]". Table 3 presents the overall evaluation of the ProQOL scales among the studied 
Table I Sample Sociodemographic Characteristics $(\mathrm{n}=334)$

\begin{tabular}{|c|c|c|}
\hline Characteristics & $\mathbf{N}$ & $\%$ \\
\hline \multicolumn{3}{|l|}{ Gender } \\
\hline Male & 58 & 17.4 \\
\hline Female & 276 & 82.6 \\
\hline \multicolumn{3}{|l|}{ Age } \\
\hline $21-25$ & 38 & 11.4 \\
\hline $26-30$ & 137 & 41.0 \\
\hline $31-35$ & 100 & 29.9 \\
\hline $36-40$ & 47 & 14.1 \\
\hline $4 I-45$ & 7 & 2.1 \\
\hline More than 45 & 5 & 1.5 \\
\hline \multicolumn{3}{|l|}{ Marital status } \\
\hline Single & 118 & 35.3 \\
\hline Married & 201 & 60.2 \\
\hline Divorced & 12 & 3.6 \\
\hline Widowed & 3 & 0.9 \\
\hline \multicolumn{3}{|l|}{ Monthly Income } \\
\hline $5000-10,000$ & 103 & 30.8 \\
\hline $10,00 \mid-15,000$ & 189 & 56.6 \\
\hline$|5,00|-20,000$ & 42 & 12.6 \\
\hline \multicolumn{3}{|l|}{ Job classification } \\
\hline Nurse specialist & 131 & 39.2 \\
\hline Nurse technician & 203 & 60.8 \\
\hline \multicolumn{3}{|l|}{ Job location } \\
\hline King Fahad Specialist Hospital & 51 & 15.3 \\
\hline King Khaled Civilian Hospital & 77 & 23.1 \\
\hline Maternal and Child Hospital & 82 & 24.6 \\
\hline Primary Health Center & 95 & 28.4 \\
\hline Psychiatry Hospital & 29 & 8.7 \\
\hline \multicolumn{3}{|l|}{ Department } \\
\hline Critical care & 125 & 37.4 \\
\hline In patient & 78 & 23.4 \\
\hline Out patient & $13 \mid$ & 39.2 \\
\hline \multicolumn{3}{|l|}{ Qualification } \\
\hline Bachelor & 129 & 38.6 \\
\hline Diploma 2 years & 112 & 33.5 \\
\hline Diploma 3 years & 93 & 27.8 \\
\hline \multicolumn{3}{|l|}{ Years of Experience } \\
\hline 16 to 20 Years & 51 & 15.3 \\
\hline II to 15 Years & 56 & 16.8 \\
\hline 6 to 10 Years & 99 & 29.6 \\
\hline I to 5 Years & 91 & 27.2 \\
\hline 6 months to I year & 15 & 4.5 \\
\hline Less than 6 months & 22 & 6.6 \\
\hline
\end{tabular}

sample. Saudi nurses reported high mean scores of CS $(41.11 \pm 8.35)$ and moderate levels of BO $(26.63 \pm 7.16)$ and STS $(28.16 \pm 7.9)$. 
Table 2 Mean Scores of CS, BO, STS According to the Sample Sociodemographic Characteristics $(n=334)$

\begin{tabular}{|c|c|c|c|c|c|c|c|c|}
\hline Characteristics & Mean CS Score & p-value & Mean BO Scale & p-value & Mean STS Scale & p-value & Mean ProQOL Scores & p-value \\
\hline Gender & & 0.093 & & 0.252 & & 0.889 & & 0.426 \\
\hline Male & $39.66 \pm 9.72$ & & $27.24 \pm 5.73$ & & $27.84 \pm 8.81$ & & $31.58 \pm 5.03$ & \\
\hline Female & $41.41 \pm 8.03$ & & $26.50 \pm 7.43$ & & $28.22 \pm 7.71$ & & $32.05 \pm 4.13$ & \\
\hline Age & & $0.008^{*}$ & & $0.012^{*}$ & & 0.112 & & 0.220 \\
\hline $21-25$ & $43.32 \pm 5.57$ & & $25.92 \pm 7.06$ & & $28.11 \pm 8.62$ & & $32.45 \pm 4.01$ & \\
\hline $26-30$ & $40.37 \pm 8.61$ & & $27.42 \pm 6.92$ & & $28.14 \pm 8.01$ & & $31.98 \pm 4.66$ & \\
\hline $31-35$ & $41.87 \pm 8.22$ & & $26.19 \pm 7.40$ & & $28.59 \pm 7.95$ & & $32.22 \pm 4.03$ & \\
\hline $36-40$ & $38.72 \pm 9.50$ & & $27.45 \pm 6.64$ & & $28.81 \pm 7.01$ & & $31.66 \pm 4.20$ & \\
\hline $4 \mid-45$ & $43.43 \pm 6.95$ & & $23.14 \pm 8.69$ & & $20.86 \pm 5.21$ & & $29.14 \pm 2.39$ & \\
\hline More than 45 & $48.40 \pm 1.67$ & & $16.60 \pm 4.72$ & & $24.40 \pm 6.66$ & & $29.80 \pm 3.46$ & \\
\hline Marital status & & 0.197 & & 0.515 & & 0.547 & & 0.839 \\
\hline Single & $41.19 \pm 8.16$ & & $26.44 \pm 6.99$ & & $28.64 \pm 8.49$ & & $32.09 \pm 4.58$ & \\
\hline Married & $40.78 \pm 8.59$ & & $26.94 \pm 7.30$ & & $27.92 \pm 7.61$ & & $31.88 \pm 4.20$ & \\
\hline Divorced & $45.00 \pm 6.35$ & & $23.67 \pm 7.13$ & & $26.75 \pm 7.79$ & & $31.81 \pm 3.59$ & \\
\hline Widowed & $44.33 \pm 2.89$ & & $25.33 \pm 1.15$ & & $30.67 \pm 2.31$ & & $33.44 \pm 1.07$ & \\
\hline Monthly Income & & 0.314 & & 0.794 & & 0.876 & & 0.498 \\
\hline $5000-10,000$ & $41.82 \pm 8.53$ & & $26.30 \pm 7.32$ & & $28.44 \pm 7.98$ & & $32.184 \pm 4.73$ & \\
\hline $10,00 \mid-15,000$ & $40.92 \pm 7.99$ & & $26.77 \pm 7.18$ & & $27.98 \pm 7.77$ & & $31.889 \pm 3.97$ & \\
\hline$|5,00|-20,000$ & $40.21 \pm 9.54$ & & $26.83 \pm 6.83$ & & $28.26 \pm 8.43$ & & $31.770 \pm 4.69$ & \\
\hline Job classification & & 0.687 & & 0.267 & & 0.851 & & 0.716 \\
\hline Nurse specialist & $41.54 \pm 6.75$ & & $27.05 \pm 6.95$ & & $28.25 \pm 8.26$ & & $32.28 \pm 4.24$ & \\
\hline Nurse technician & $40.83 \pm 9.25$ & & $26.36 \pm 7.30$ & & $28.09 \pm 7.69$ & & $31.76 \pm 4.33$ & \\
\hline Job location & & 0.167 & & $<0.001 *$ & & $<0.001 *$ & & $<0.00 I^{*}$ \\
\hline King Fahad Specialist Hospital & $42.35 \pm 9.01$ & & $23.51 \pm 7.65$ & & $24.65 \pm 7.62$ & & $30.17 \pm 4.15$ & \\
\hline King Khaled Civilian Hospital & $39.31 \pm 10.03$ & & $27.78 \pm 7.90$ & & $28.95 \pm 7.71$ & & $32.01 \pm 4.06$ & \\
\hline Maternal and Child Hospital & $40.18 \pm 8.78$ & & $24.88 \pm 7.69$ & & $25.45 \pm 6.81$ & & $30.17 \pm 3.61$ & \\
\hline Primary Health Center & $41.94 \pm 6.52$ & & $27.86 \pm 5.44$ & & $30.12 \pm 7.81$ & & $33.31 \pm 4.13$ & \\
\hline Psychiatry Hospital & $43.59 \pm 4.90$ & & $30.00 \pm 4.32$ & & $33.45 \pm 7.14$ & & $35.68 \pm 3.63$ & \\
\hline Department & & 0.720 & & 0.003 & & 0.008 & & $<0.001$ \\
\hline Critical care & $41.31 \pm 7.33$ & & $27.39 \pm 7.21$ & & $28.86 \pm 7.36$ & & $32.52 \pm 3.82$ & \\
\hline In patient & $42.09 \pm 7.17$ & & $28.08 \pm 7.26$ & & $29.68 \pm 7.93$ & & $33.28 \pm 3.72$ & \\
\hline Out patient & $40.33 \pm 9.80$ & & $25.05 \pm 6.80$ & & $26.57 \pm 8.16$ & & $30.65 \pm 4.70$ & \\
\hline Qualification & & 0.201 & & 0.459 & & 0.440 & & 0.208 \\
\hline Bachelor & $41.51 \pm 6.75$ & & $26.98 \pm 6.98$ & & $28.11 \pm 8.17$ & & $32.20 \pm 4.17$ & \\
\hline Diploma 2 years & $42.69 \pm 6.73$ & & $25.78 \pm 7.03$ & & $29.08 \pm 7.18$ & & $32.52 \pm 3.93$ & \\
\hline Diploma 3 years & $39.33 \pm 10.68$ & & $26.93 \pm 7.48$ & & $27.45 \pm 8.15$ & & $31.24 \pm 4.64$ & \\
\hline
\end{tabular}


Table 2 (Continued).

\begin{tabular}{|c|c|c|c|c|c|c|c|c|}
\hline Characteristics & Mean CS Score & p-value & Mean BO Scale & p-value & Mean STS Scale & p-value & Mean ProQOL Scores & p-value \\
\hline Years of Experience & & $0.012^{*}$ & & 0.061 & & 0.141 & & 0.102 \\
\hline 16 to 20 Years & $39.92 \pm 9.11$ & & $26.18 \pm 7.93$ & & $27.53 \pm 7.83$ & & $31.21 \pm 4.03$ & \\
\hline II to 15 Years & $38.09 \pm 10.82$ & & $27.48 \pm 7.89$ & & $27.87 \pm 8.46$ & & $31.15 \pm 4.48$ & \\
\hline 6 to 10 Years & $43.24 \pm 6.13$ & & $25.95 \pm 6.70$ & & $28.07 \pm 6.68$ & & $32.42 \pm 3.57$ & \\
\hline I to 5 Years & $40.75 \pm 8.08$ & & $27.65 \pm 6.22$ & & $29.12 \pm 8.19$ & & $32.51 \pm 4.79$ & \\
\hline 6 months to I year & $40.07 \pm 6.95$ & & $28.40 \pm 7.53$ & & $30.60 \pm 7.59$ & & $33.02 \pm 3.52$ & \\
\hline Less than 6 months & $44.14 \pm 7.47$ & & $23.18 \pm 7.97$ & & $25.05 \pm 10.17$ & & $30.79 \pm 5.25$ & \\
\hline
\end{tabular}

Notes: Mann-Whitney $\mathrm{U}$ and Kruskal-Wallis tests. *Significance level at $\mathrm{p}>0.05$

Abbreviations: CS, compassion satisfaction; CF, compassion fatigue; BO, burnout; STS, secondary traumatic stress. 


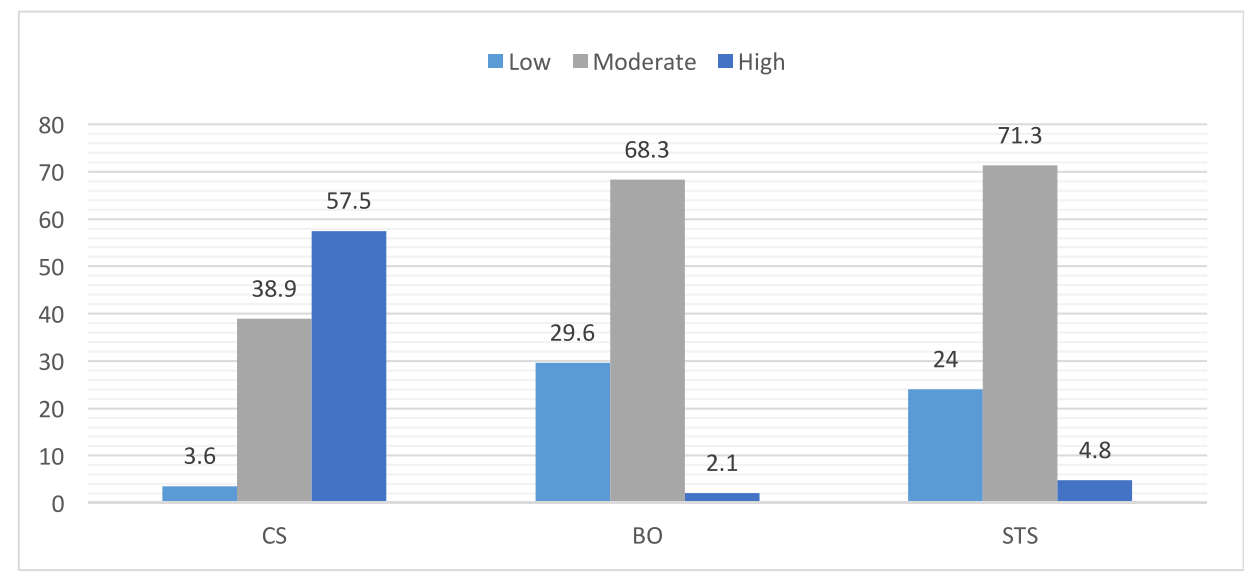

Abbreviations: CS - compassion satisfaction; $\mathrm{CF}$ - compassion fatigue; $\mathrm{BO}-$ burnout; STS - secondary traumatic stress.

Figure I Sample distribution according to subscale levels (\%) (n-334).

Abbreviations: CS, compassion satisfaction; CF, compassion fatigue; $\mathrm{BO}$, burnout; STS, secondary traumatic stress.

\section{Discussion}

Currently, Saudi Arabia is witnessing a significant change in the health care delivery system to meet the mandates of Saudi Vision 2030. ${ }^{24}$ The nursing profession is the cornerstone of the health care system. This study was conducted to explore whether sociodemographic factors were associated with Saudi nurses' ProQOL and their CS, BO, and STS mean scores. Based on our findings, personal factors were not associated with levels and mean scores of ProQOL subscales, except for age, the mean of CS was higher among nurses aged more than 45 years; thus, CS is significantly associated with older age. However, this is contradictory to other studies that have reported that nurses' ages negatively correlate with their level of CS and that lower levels of CS are related to older age. ${ }^{15,28}$ Our findings reveal that nurses aged between 36 and 40 years had less CS and greater levels of BO. This finding contradicts Sacco, Ciurzynski, Harvey and Ingersoll, ${ }^{15}$ who stated that increasing age is related to greater levels of BO. Older nurses have the maturity to deal with patients in different situations, while nurses at younger ages lack this experience. In this study, both CS and BO correlated with age. This is consistent with the previously mentioned studies where age groups were associated with lower CS and higher BO; it is also supported by a meta-analysis by Zhang, Zhang, Han, Li, and Wang. ${ }^{29}$

Regarding work-related variables, nurses working in mental health hospitals exhibited higher BO mean scores due to the nature of their work dealing with psychiatric patients; this is supported by Alqahtani, Al-Otaibi, and Zafar, ${ }^{30}$ who observed a high prevalence of BO among psychiatric nurses, particularly of Saudi nationality. The department scored a significant difference with mean scores of CS and BO. It was expected that critical care nurses would score lower for CS and higher for BO and STS, as mentioned by other studies. ${ }^{15,31,32}$ In the current study, unexpectedly, nurses working at inpatient units reported high levels of CS and moderate levels of BO; high mean scores for BO and STS were observed

Table 3 CS, BO, and STS Among the Sample of Saudi Nurses $(n=334)$

\begin{tabular}{|l|l|l|l|l|l|}
\hline \multicolumn{2}{|l|}{ ProQoL Subscales } & M & SD & Min & Max \\
\hline CS & 41.11 & 8.35 & 10 & 50 \\
\hline CF & BO & 26.63 & 7.162 & 10 & 46 \\
\cline { 2 - 7 } & STS & 28.16 & 7.902 & 10 & 50 \\
\hline $\begin{array}{l}\text { Mean subscale } \\
\text { scores }\end{array}$ & 31.965 & 4.295 & - & - \\
\hline
\end{tabular}

Abbreviations: CS, compassion satisfaction; CF, compassion fatigue; BO, burnout; STS, secondary traumatic stress. 
among the same group. This may be due to the continuous routine work of inpatient nurses and the continued exposure to chronically ill patients. The ProQOL among nurses working at inpatient units has not been sufficiently explored; most of the studies have focused on nurses working with critical care, emergency, terminally-ill, and oncology patients. . $^{614,19,22,23}$

Many studies have not found a significant relationship between nurses' years of experience and ProQOL aspects. ${ }^{8,28,33}$ Conversely, the factor of years of nursing experience showed significance with mean scores of CS; newly employed nurses with less than 6 months of experience had a significantly higher mean score for CS compared to other nurses. New nurses may not have the opportunity to experience many stressful situations. Additionally, it is expected that these nurses have a mentor or are under a probationary period. These findings are in line with a study by Mooney, Fetter, Gross, Rinehart, Lynch and Rogers ${ }^{31}$ that found that years of experience led to a significant decrease in CF, encompassing BO and STS.

Saudi nurses exhibit high levels of CS like nurses in countries all over the world, including Latvia, India, Spain, and South Korea. ${ }^{28,33-35}$ The levels of BO and STS experienced by Saudi nurses were scored at a moderate level, similar to American, Chinese, Korean, and Filipino nurses. ${ }^{21,31,33,36}$

This study provides a glance at the ProQOL of Saudi nurses who generally exhibit high levels of CS and moderate levels of BO and STS. This is a good indicator of the satisfaction levels among Saudi nurses but also indicates a risk of future BO and STS.

\section{Conclusion}

For Saudi nursing professionals, the CS level was satisfactory; however, the BO and STS levels need to be addressed further. Improving CS and addressing CF difficulties would benefit Saudi Arabian nursing profession. This study explored Saudi nurses' CS and CF and its associated factors to inform legislators and decision-makers for the nursing profession's future direction to achieve the Saudi National Transformational Program-related goals.

The cross-sectional nature of the study could be one of its limitations. The generalisability of the findings cannot be guaranteed as a convenience sample was used. The study instrument was self-reported so there was a risk of response bias (eg, the participants attempting to please the researcher). Further analysis is recommended to determine the factors influencing all aspects of ProQOL besides the personal and professional factors examined here.

\section{Acknowledgments}

The author would like to thank the hospital staff and appreciate the efforts of health care center coordinators Khloud Dagriry, Bashyer Asesri, Nawader Alunizi, and Issa Alghamdi, who facilitated online data collection.

\section{Funding}

No funding was provided for this study.

\section{Disclosure}

The authors declare no conflicts of interest in this study.

\section{References}

1. Tumulty G. Professional development of nursing in Saudi Arabia. J Nurs Scholarsh. 2001;33(3):285-290. doi:10.1111/j.1547-5069.2001.00285.x

2. Alboliteeh M, Magarey J, Wiechula R. The profile of Saudi nursing workforce: a Cross-Sectional Study. Nurs Res Pract. 2017;2017:1710686. doi:10.1155/2017/1710686

3. Almalki M, FitzGerald G, Clark M. The nursing profession in Saudi Arabia: an overview. Int Nurs Rev. 2011;58(3):304-311. doi:10.1111/j.14667657.2011.00890.x

4. Lamadah S. Challenges facing nursing profession in Saudi Arabia. J Biol Agric Healthc. 2014;4(7):20-25.

5. Aboshaiqah A. Strategies to address the nursing shortage in Saudi Arabia. Int Nurs Rev. 2016;63(3):499-506. doi:10.1111/inr.12271

6. Shaker Saati HS. Compassion fatigue, satisfaction and burnout among oncology nurses working in pediatric oncology setting. Biosc Biotech Res Commun. 2020;13(3):1314-1320. doi:10.21786/bbrc/13.3/50

7. Albougami AS, Almazan JU, Cruz JP, et al. Factors affecting nurses' intention to leave their current jobs in Saudi Arabia. Int J Health Sci. 2020;14 (3):33-40.

8. Hegney DG, Rees CS, Eley R, Osseiran-Moisson R, Francis K. The contribution of individual psychological resilience in determining the professional quality of life of Australian nurses. Front Psychol. 2015;6(1613):1613. doi:10.3389/fpsyg.2015.01613 
9. Stamm BH. The Concise ProQOL Manual. Pocatello, ID: proqol. org; 2010.

10. Stamm B, Figley C. Advances in the Theory of Compassion Satisfaction and Fatigue and Its Measurement with the ProQOL 5. Atlanta: International Society for Traumatic Stress Studies; 2009.

11. McEvoy L, Duffy A. Holistic practice-a concept analysis. Nurse Educ Pract. 2008;8(6):412-419. doi:10.1016/j.nepr.2008.02.002

12. Yilmaz G. Professional quality of life in nurses: compassion satisfaction and compassion fatigue. J Psychiatr Nurs. $2018 ; 9(3)$ :205-211.

13. Lartey JKS, Osafo J, Andoh-Arthur J, Asante KO. Emotional experiences and coping strategies of nursing and midwifery practitioners in Ghana: a qualitative study. BMC Nurs. 2020;19(1):92. doi:10.1186/s12912-020-00484-0

14. Wu S, Singh-Carlson S, Odell A, Reynolds G, Su Y. Compassion fatigue, burnout, and compassion satisfaction among oncology nurses in the United States and Canada. Oncol Nurs Forum. 2016;43(4):E161-E169. doi:10.1188/16.ONF.E161-E169

15. Sacco TL, Ciurzynski SM, Harvey ME, Ingersoll GL. Compassion satisfaction and compassion fatigue among critical care nurses. Crit Care Nurse. 2015;35(4):32-43; quiz 31p following 43. doi:10.4037/ccn2015392

16. Muliira RS, Ssendikadiwa VB. Professional quality of life and associated factors among Ugandan midwives working in Mubende and Mityana rural districts. Matern Child Health J. 2016;20(3):567-576. doi:10.1007/s10995-015-1855-2

17. Amin AA, Vankar JR, Nimbalkar SM, Phatak AG. Perceived stress and professional quality of life in neonatal intensive care unit nurses in Gujarat, India. Indian J Pediatr. 2015;82(11):1001-1005. doi:10.1007/s12098-015-1794-3

18. Dall'Ora C, Ball J, Reinius M, Griffiths P. Burnout in nursing: a theoretical review. Hum Resour Health. 2020;18(1):41. doi:10.1186/s12960-020$00469-9$

19. Oginska-Bulik N, Michalska P. Psychological resilience and secondary traumatic stress in nurses working with terminally ill patients-the mediating role of job burnout. Psychol Serv. 2021;18(3):398-405. doi:10.1037/ser0000421

20. Arnold TC. An evolutionary concept analysis of secondary traumatic stress in nurses. Nurs Forum. 2020;55(2):149-156. doi:10.1111/ nuf. 12409

21. Wang J, Okoli CTC, He H, et al. Factors associated with compassion satisfaction, burnout, and secondary traumatic stress among Chinese nurses in tertiary hospitals: a cross-sectional study. Int J Nurs Stud. 2020;102:103472. doi:10.1016/j.ijnurstu.2019.103472

22. Ratrout HF, Hamdan-Mansour AM. Secondary traumatic stress among emergency nurses: prevalence, predictors, and consequences. Int $J$ Nurs Pract. 2020;26(1):e12767. doi:10.1111/ijn.12767

23. Alharbi J, Jackson D, Usher K. Compassion fatigue in critical care nurses and its impact on nurse-sensitive indicators in Saudi Arabian hospitals. Aust Crit Care. 2020;33(6):553-559. doi:10.1016/j.aucc.2020.02.002

24. Al-Hanawi MK, Khan SA, Al-Borie HM. Healthcare human resource development in Saudi Arabia: emerging challenges and opportunities-a critical review. Public Health Rev. 2019;40:1. doi:10.1186/s40985-019-0112-4

25. Nunnally J, Bernstein I. Psychometric Theory. McGraw-Hill Companies, Incorporated; 1994.

26. Carmines EG, Zeller RA. Reliability and Validity Assessment. Sage publications; 1979.

27. Fincham JE. Response rates and responsiveness for surveys, standards, and the journal. Am J Pharm Educ. 2008;72(2):43. doi:10.5688/aj720243

28. Ruiz-Fernandez MD, Perez-Garcia E, Ortega-Galan AM. Quality of life in nursing professionals: burnout, fatigue, and compassion satisfaction. Int J Environ Res Public Health. 2020;17(4):1253. doi:10.3390/ijerph17041253

29. Zhang YY, Zhang C, Han XR, Li W, Wang YL. Determinants of compassion satisfaction, compassion fatigue and burn out in nursing: a correlative meta-analysis. Medicine. 2018;97(26):e11086. doi:10.1097/MD.0000000000011086

30. Alqahtani R, Al-Otaibi S, Zafar M. Burnout syndrome among nurses in a psychiatric hospital in Dammam, Saudi Arabia. Nurs Midwifery Stud. 2020;9(2):110-115. doi:10.4103/nms.nms_126_19

31. Mooney C, Fetter K, Gross BW, et al. Analysis of compassion satisfaction and compassion fatigue with considerations for nursing unit specialization and demographic factors. J Trauma Nurs. 2017;24(3):158-163. doi:10.1097/JTN.0000000000000284

32. Alotni MA, Elgazzar SE. Investigation of burnout, its associated factors and its effect on the quality of life of critical care nurses working in Buraydah Central Hospital at Qassim Region, Saudi Arabia. Open Nurs J. 2020;14(1):190-202. doi:10.2174/1874434602014010190

33. Kim K, Han Y, Kwak Y, Kim JS. Professional quality of life and clinical competencies among Korean Nurses. Asian Nurs Res. 2015;9(3):200-206. doi:10.1016/j.anr.2015.03.002

34. Circenis K, Millere I, Deklava L. Measuring the professional quality of life among Latvian nurses. Procd Soc Behv. 2013;84:1625-1629. doi:10.1016/j.sbspro.2013.07.003

35. Pramilaa R. A descriptive correlational study on compassion and professional quality of life among nurses. Int $J$ Nurs Educ. 2018;10(1). doi:10.5958/0974-9357.2018.00028.4

36. Adolfo CS. Predictors of professional quality of life among nurses-a cross sectional study. Int J Adv Appl Sci. 2021;8(2):44-53. doi:10.21833/ ijaas.2021.02.006

Nursing: Research and Reviews

Dovepress

\section{Publish your work in this journal}

Nursing: Research and Reviews is an international, peer-reviewed, open access journal publishing original research, reports, reviews and commentaries on all aspects of nursing and patient care. These include patient education and counseling, ethics, management and organizational issues, diagnostics and prescribing, health outcomes, economics and resource management, improving patient safety in all settings. The manuscript management system is completely online and includes a very quick and fair peer-review system. Visit http://www.dovepress.com/ testimonials.php to read real quotes from published authors.

Submit your manuscript here: http://www.dovepress.com/nursing-research-and-reviews-journal 